\title{
Mechanism of Reduced Glomerular Filtration Rate in Chronic Malnutrition
}

\author{
Iekuni Ichikawa, Mabel L. Purkerson, Saulo Klahr, Julia L. Troy, \\ Manuel Martinez-Maldonado, and Barry M. Brenner, Laboratory of Kidney \\ and Electrolyte Physiology, Departments of Medicine, Peter Bent Brigham \\ Hospital and Harvard Medical School, Boston, Massachusetts 02115; \\ Renal Division, Department of Medicine, Washington University School \\ of Medicine, St. Louis, Missouri 63110
}

A B S T RACT To determine the physiological basis for the low glomerular filtration rate in chronic malnutrition, micropuncture studies were performed in Munich-Wistar rats chronically pair-fed isocaloric diets of either low (group 1, nine rats) or high protein content (group 2, nine rats). Despite the absence of hypoalbuminemia, average values for single nephron and total kidney glomerular filtration rate were nearly $35 \%$ lower in group 1 than in group 2 . Mean values for glomerular capillary and Bowman's space hydraulic pressures were essentially identical in the two groups, thereby excluding glomerular transcapillary hydraulic pressure difference as the cause for the low filtration rates in group 1 animals. On the other hand, average glomerular capillary plasma flow rate and glomerular capillary ultrafiltration coefficient were significantly lower (by $\sim 25$ and $\sim 50 \%$, respectively) in group 1 than in group 2 . The fall in glomerular capillary plasma flow rate was the consequence of increased afferent and efferent arteriolar resistances. Plasma and erythrocyte volumes were found to be equal in five additional pairs of group 1 and group 2 rats. Thus, the substantial alterations in the ultrafiltration coefficient, glomerular capillary plasma flow rate, and renal arteriolar resistances responsible for the low filtration rate in group 1 animals were not merely a consequence of decreased circulating blood or plasma volumes. Mean values for glomerular cross sectional area were significantly lower in group 1 than in group 2 despite similar values for kidney weight in the two groups. This reduction in glomerular cross sectional area in group 1 rats is presumed to

Portions of this work were presented in part at the 11th Annual Meeting of The American Society of Nephrology, New Orleans, La., 21 November 1978 and published in abstract form: 1979. American Society of Nephrology. 11: 91A.

Received for publication 16 October 1979 and in revised form 14 December 1979. reflect a decrease in effective filtration surface area and therefore likely accounts, at least in part, for the decline in ultrafiltration coefficient observed in this group.

Finally, since the daily caloric intake of group 2 animals was restricted because of pair feeding requirements tied to the group 1 rats, we studied a third group of seven rats (group 3) allowed an ad lib. intake of the same high protein diet as given to group 2 rats. Average values for single nephron glomerular filtration rate and its determinants were found to be indistinguishable between groups 2 and 3 . These results suggest that low protein intake, rather than calorie deficiency per se, is primarily responsible for the reduction in filtration rate seen in this experimental model of chronic malnutrition.

\section{INTRODUCTION}

Reductions in glomerular filtration rate (GFR) and renal plasma flow rate are often found in chronically malnourished subjects (1-3). Given that chronic malnutrition is a health problem of major epidemiological importance world-wide, elucidation of the mechanisms responsible for these alterations in renal function appears warranted. We therefore undertook to characterize the various hemodynamic determinants of glomerular filtration under carefully controlled nutritional conditions in the Munich-Wistar rat. Rats were pair-fed isocaloric diets that were either rich or poor in protein content. Because the total caloric intake in these two pair-fed groups was less than normal, a third group of rats was fed the high protein diet in ad lib. quantities, thereby enabling us to define the effects on renal function of selective protein and calorie malnutrition.

\section{GLOSSARY OF SYMBOLS}

$\overline{\mathrm{AP}}$ Mean femoral arterial pressure, $\mathrm{mm} \mathrm{Hg}$

C Protein concentration, g/dl 
GFR Glomerular filtration rate (whole kidney), $\mathrm{ml} / \mathrm{min}$

Hct Blood hematocrit in femoral artery, vol\%

$\mathrm{K}_{\mathrm{f}}$ Ultrafiltration coefficient, $\mathrm{nl} /(\mathrm{s} \cdot \mathrm{mm} \mathrm{Hg})$

$\mathrm{P}$ Hydraulic pressure, $\mathrm{mm} \mathrm{Hg}$

$\Delta \mathrm{P}$ Transcapillary hydraulic pressure difference, $\mathrm{P}_{\mathrm{GC}}-\mathrm{P}_{\mathrm{T}}, \mathrm{mm} \mathrm{Hg}$

$\pi$ Colloid osmotic pressure, $\mathrm{mm} \mathrm{Hg}$

$Q_{A}$ Initial glomerular capillary plasma flow rate, $\mathrm{nl} / \mathrm{min}$

$\mathrm{R}$ Resistance to blood flow, dyn $\cdot \mathrm{s} \cdot \mathrm{cm}^{-5}$

$R_{T A}$ Total arteriolar resistance, $R_{A}+R_{E}$, dyn $\cdot s \cdot \mathrm{cm}^{-5}$

SNFF Single nephron filtration fraction

SNGFR Single nephron glomerular filtration rate, $\mathrm{nl} / \mathrm{min}$

\section{Superscript}

- Mean value

\section{Subscripts}

A Femoral artery or afferent arteriole

C Peritubular capillary

E Efferent arteriole

GC Glomerular capillary

T Proximal tubule

\section{METHODS}

General. 28 1-mo-old Munich-Wistar rats weighing $\sim 90 \mathrm{~g}$ were pair-fed pulverized isocaloric diets of either low or high protein content for 4 mo. The low protein diet contained (on a weight basis) $6 \%$ protein (micropulverized vitamin-free casein, ICN Nutritional Biochemical Co., Cleveland, Ohio) and $78.8 \%$ carbohydrate $(35 \%$ sucrose, $43.8 \%$ dextrin). Animals fed this diet constitute group 1 . The high protein diet contained $40.0 \%$ casein and $44.8 \%$ carbohydrate $(20 \%$ sucrose, $24.8 \%$ dextrin). Animals fed this diet constitute group 2. The fat (corn oil), vitamin (vitamin supplement for rats, ICN Nutritional Biochemical Co.), cystine, and mineral (Na-free salt mixture, ICN Nutritional Biochemical Co.) content of both diets was identical, comprising $7,2,0.2$, and $4 \%$, respectively. Each diet contained 0.069 meq of $\mathrm{Na}$ and 0.16 meq of $\mathrm{K}$ per gram. Pairing of rats was carried out on the basis of body weight, after which paired rats were fed their respective diets and maintained in individual metabolic cages throughout. They were weighed daily and offered tap water ad lib. The member of each pair on the high protein diet received the identical gram-weight of food that its low protein diet counterpart had consumed during the previous 24 -h period. A third group of nine 1-mo-old rats (group 3) was allowed the high protein diet ad lib. for $\sim 2$ mo.

Micropuncture measurements. 25 rats (9 of group 1, 9 of group 2 , and 7 of group 3 ) were subjected to micropuncture studies when they achieved body weights of 150-202 $\mathrm{g}$ (i.e., group 1 and 2 rats were $\sim 5$ mo old and group 3 rats $\sim 3$ mo old). Routine surgical preparation for micropuncture (4) was carried out immediately after induction of anesthesia with Inactin, Byk Gulden Konstanz, West Germany $(100 \mathrm{mg} / \mathrm{kg}$ body wt, i.p.). Both members of a pair were studied on the same day and by the same micropuncturist. Throughout the period of surgical preparation and experimental study, each animal received a continuous intravenous infusion of isoncotic rat plasma (total $\sim 1 \%$ body wt) to maintain normal circulating plasma volume. The details of this protocol and its justification are given elsewhere (4). Concomitant with the surgical preparation, an intravenous infusion of $6 \%$ inulin solution in $0.9 \% \mathrm{NaCl}$ was begun and continued throughout the duration of each experiment at the rate of $1.2 \mathrm{ml} / \mathrm{h}$.
After a 60 -min equilibration period, micropuncture measurements were carried out as follows: Exactly timed (1-2 min) samples of tubule fluid were collected from surface proximal convolutions of two or three nephrons of the left kidney for determination of flow rate and inulin concentration and calculation of single nephron glomerular filtration rate (SNGFR). Inulin concentration in tubule fluid was measured by the method of Vurek and Pegram (5). Coincident with these tubule fluid collections, two or three samples of femoral arterial blood were obtained in each period for determination of hematocrit (Hct) and plasma concentrations of protein and inulin. In addition, two or three samples of urine from the left kidney were collected for determination of flow rate, inulin concentration, and calculation of whole kidney GFR. Plasma and urine inulin concentrations were assayed by the microanthrone method of Führ et al. (6). Samples of blood from two or three superficial efferent arterioles were also obtained, as described (7), and analyzed for total plasma protein concentration by the method of Viets et al. (8). Samples of femoral arterial blood plasma were analyzed similarly. From these measurements of protein concentration $(\mathrm{C})$, which are taken as representative of afferent and efferent arteriolar plasma $\left(C_{A}\right.$ and $C_{E}$, respectively), values for afferent and efferent arteriolar oncotic pressure $\left(\pi_{\mathrm{A}}\right.$ and $\left.\pi_{\mathrm{E}}\right)$ were calculated, using the equation derived by Deen et al. $(9,10)$. Also these measurements of $C_{A}$ and $C_{E}$ permit calculation of single nephron filtration fraction (SNFF) and initial glomerular capillary plasma flow rate $\left(Q_{A}\right)$, using equations given below. Time averaged pressures were measured in surface glomerular capillaries $\left(\mathrm{P}_{\mathrm{GC}}\right)$, proximal tubules $\left(P_{T}\right)$, and third-order peritubular capillaries $\left(P_{C}\right)$ using a continuous recording, servo-null micropipette transducer system (11). These measurements permit calculation of the glomerular capillary ultrafiltration coefficient $\left(\mathrm{K}_{\mathrm{f}}\right)$, as well as resistances of single afferent $\left(R_{A}\right)$ and efferent $\left(R_{E}\right)$ arterioles and total renal arteriolar resistance $\left(R_{T A}\right)$.

\section{Calculations}

Single nephron filtration fraction:

$$
\mathrm{SNFF}=1-\mathrm{C}_{\mathrm{A}} / \mathrm{C}_{\mathrm{E}} .
$$

Initial glomerular capillary plasma flow rate:

$$
\mathrm{Q}_{\mathrm{A}}=\mathrm{SNGFR/SNFF} \text {. }
$$

Blood flow rate per single afferent arteriole or glomerulus:

$$
\mathrm{GBF}=\mathrm{Q}_{\mathrm{A}} /(1-\mathrm{Hct}) \text {. }
$$

Efferent arteriolar blood flow (EABF) rate:

$$
\mathrm{EABF}=\mathrm{GBF}-\mathrm{SNGFR} \text {. }
$$

Resistance per single afferent arteriole:

$$
\mathbf{R}_{\mathrm{A}}=\left[\left(\overline{\mathrm{AP}}-\overline{\mathrm{P}}_{\mathrm{GC}}\right) / \mathrm{GBF}\right] \times\left(7.962 \times 10^{10}\right),
$$

where the factor $7.962 \times 10^{10}$ is used to give resistance in units of $\mathrm{dyn} \cdot \mathrm{s} \cdot \mathrm{cm}^{-5}$ when $\overline{\mathrm{AP}}$ and $\overline{\mathrm{P}}_{\mathrm{GC}}$ are expressed in $\mathrm{mm} \mathrm{Hg}$ and $\mathrm{GBF}$ in nanoliter per minute.

Resistance per single efferent arteriole:

$$
\mathbf{R}_{\mathrm{E}}=\left[\left(\overline{\mathrm{P}}_{\mathrm{GC}}-\mathrm{P}_{\mathrm{C}}\right) / \mathrm{EABF}\right] \times\left(7.962 \times 10^{10}\right) .
$$

Total arteriolar resistance for a single pre- to postglomerular vascular unit:

$$
\mathbf{R}_{\mathrm{TA}}=\mathbf{R}_{\mathrm{A}}+\mathbf{R}_{\mathbf{E}}
$$


Mean glomerular transcapillary hydraulic pressure difference:

$$
\overline{\Delta \mathrm{P}}=\overline{\mathrm{P}}_{\mathrm{GC}}-\mathrm{P}_{\mathrm{T}} \text {. }
$$

The $K_{f}$ is calculated with a differential equation that gives the rate of change of plasma protein concentration with distance along an idealized glomerular capillary. This equation, together with its derivation and the method for its solution, is given in detail elsewhere (9).

Measurements of plasma volume and erythrocyte volume. In five pairs of group 1 and 2 rats, circulating plasma and erythrocyte volumes were measured immediately after induction of anesthesia with catheterization of the left femoral artery and vein. The erythrocyte and plasma volumes at this stage, i.e., before abdominal and neck surgery, were previously shown to be equal to values in conscious (euvolemic) animals (4). Circulating erythrocyte volume was determined by the technique of Sterling and Gray (12), using $0.4 \mathrm{ml}$ of ${ }^{5} \mathrm{Cr}$-labeled erythrocytes harvested from donor MunichWistar rats [New England Nuclear (Boston, Mass.), 15 $\mu \mathrm{Ci} / \mathrm{ml} \mathrm{sp}$ act of whole blood]. Plasma volume was measured by a modification (13) of the technique of Crispell et al. (14), using $\sim 5.0 \mu \mathrm{Ci}$ of ${ }^{125}$ I-labeled bovine serum albumin (New England Nuclear, $\sim 1.0 \mathrm{mCi} / \mathrm{mg}$ sp act). After periodic collections of blood samples for these measurements, routine surgical preparation and plasma infusion were performed for determination of whole kidney GFR.

Morphological studies. Upon conclusion of functional studies in nine pairs of group 1 and 2 rats and nine group 3 rats, kidneys were removed, fixed in buffered formalin and divided in half by mid-coronal section. Tissue was prepared for light microscopic examination by standard histologic techniques, paraffin sections were cut to $2-4 \mu \mathrm{m}$ thickness, and stained with periodic acid Schiff. The mid-coronal sections were used to obtain camera lucida drawings of subcapsular cortical glomeruli. Particular attention was given to selection of the glomeruli for measurement. Only those in which afferent and efferent vessels could be seen to be attached to the renal corpuscle and in which the early proximal tubule could be seen to emanate from Bowman's capsule were used. In this manner, we could be confident of displaying the area of greatest diameter of each renal corpuscle. 50 glomeruli from each kidney were measured. Camera lucida drawings were made at $\times 417$. A computer system (15) was used for measurements of glomerular outlines and calcula- tion of cross-sectional area (expressed in square microns). This system integrates the area within a closed profile such as a renal corpuscle and takes into account the original magnification of the drawings. These data are not corrected for shrinkage in fixation and processing.

For transmission electron microscopy, five pairs of rats from groups 1 and 2 were used. The cortical surface of the left kidney from each rat was fixed in vivo by drip fixation over a 5 -min period with a $1.5 \%$ glutaraldehyde in $0.1 \mathrm{M}$ sodium-cacodylate buffer ( $\mathrm{pH} 7.35,383$ mosmol). Cortical portions of each kidney were removed and placed in cold $0.1 \mathrm{M}$ sodium cacodylate buffer with $1.5 \%$ glutaraldehyde (PolyScience Corp., Niles, Ill.) for $1 \mathrm{~h}$ and postfixed in $1 \%$ osmium tetroxide, in Dalton's buffer ( $\mathrm{pH}$ 7.6). Tissues were dehydrated through a graded series of alcohols and embedded in Spurr's low viscosity embedding medium. Thin sections were stained with uranyl acetate and lead citrate and examined in the electron microscope.

\section{RESULTS}

General. Table I summarizes the results of whole animal data obtained in groups 1-3. Body weight was significantly lower in group 1 than in group 2, despite identical daily caloric intake. Kidney weight was also less in group 1 than group 2 but the difference did not achieve statistical significance. Values for Hct were slightly but significantly lower in group 1 than group 2 . Since erythrocyte volumes (see below) were essentially the same in both groups when corrected for body weight, this low Hct value of group 1 reflects a relatively larger plasma volume, on a body weight basis, in this group. Despite remarkably low daily protein intake in group 1 animals, average values for $C_{A}$ were only slightly, though significantly, lower in group 1 than group 2. Whole kidney GFR was substantially lower in group 1 than group 2. No differences in any of these quantities were discerned between groups 2 and 3 .

Micropuncture measurements. Table II summarizes mean values for SNGFR and its determinants

TABLE I

Whole Animal Data Obtained from Groups 1-3

\begin{tabular}{|c|c|c|c|c|c|c|}
\hline & BW & $\mathrm{KW}$ & Het & $\mathrm{C}_{\mathrm{A}}$ & $\overline{\mathrm{AP}}$ & GFR \\
\hline & \multicolumn{2}{|c|}{$g$} & vol\% & $g / d l$ & $m m \mathrm{Hg}$ & $\mathrm{ml} / \mathrm{min}$ \\
\hline Group 1 & 169 & 0.73 & 43.6 & 5.4 & 114 & 0.59 \\
\hline$(n=14$ rats $)$ & \pm 4 & 0.01 & 0.5 & 0.1 & 2 & 0.04 \\
\hline Group 2 & 187 & 0.77 & 45.7 & 5.6 & 116 & 0.79 \\
\hline$(n=14$ rats $)$ & 6 & 0.02 & 0.5 & 0.1 & 2 & 0.03 \\
\hline Group 3 & 182 & 0.77 & 46.1 & 5.7 & 116 & 0.81 \\
\hline ( $n=7$ rats $)$ & 5 & 0.02 & 0.6 & 0.1 & 4 & 0.07 \\
\hline$P$ value* & $<0.025$ & $>0.05$ & $<0.005$ & $<0.025$ & $>0.20$ & $<0.005$ \\
\hline$P$ value & $>0.50$ & $>0.50$ & $>0.50$ & $>0.50$ & $>0.50$ & $>0.50$ \\
\hline
\end{tabular}

Values are expressed as mean $\pm 1 \mathrm{SE}$.

* Calculated from paired data for the values of group $1 \mathrm{vs} .2$.

\$ Calculated from unpaired data for the values of group 2 vs. 3 . 
TABLE II

Summary of Single Nephron Function as Measured in Groups 1-3

\begin{tabular}{|c|c|c|c|c|c|c|c|c|c|c|c|c|}
\hline & SNGFR & $\tilde{\mathrm{P}}_{\mathrm{GC}}$ & $\mathrm{P}_{\mathrm{T}}$ & $\overline{\Delta \mathbf{P}}$ & $\Pi_{\mathrm{A}}$ & $\Pi_{\mathbf{E}}$ & $Q_{A}$ & SNFF & $\mathbf{R}_{\mathbf{A}}$ & $R_{E}$ & $\mathbf{R}_{\mathrm{TA}}$ & $K_{\mathrm{f}}$ \\
\hline & $n l / m i n$ & & & $m m \mathrm{Hg}$ & & & $n l / m i n$ & & & $0^{10} d y n \cdot s \cdot c r$ & & $n l(s \cdot m m H g)$ \\
\hline \multirow{2}{*}{$\begin{array}{l}\text { Group } 1 \\
\quad(n=9 \text { rats })\end{array}$} & 20.5 & 49.6 & 14.0 & 35.6 & 17.4 & 30.6 & 68 & 0.31 & 4.3 & 3.4 & 7.7 & 0.034 \\
\hline & \pm 1.3 & 0.9 & 0.7 & 0.5 & 0.4 & 1.2 & 5 & 0.01 & 0.3 & 0.2 & 0.5 & 0.003 \\
\hline \multirow{2}{*}{$\begin{array}{l}\text { Group } 2 \\
\quad(n=9 \text { rats })\end{array}$} & 30.0 & 47.8 & 13.4 & 34.3 & 18.5 & 33.5 & 91 & 0.32 & 3.5 & 2.6 & 6.1 & $0.065 \S$ \\
\hline & 3.1 & 0.6 & 0.5 & 0.8 & 0.6 & 1.4 & 10 & 0.01 & 0.5 & 0.3 & 0.7 & 0.006 \\
\hline \multirow{2}{*}{$\begin{array}{l}\text { Group } 3 \\
\quad(n=7 \text { rats })\end{array}$} & 30.6 & 48.0 & 13.1 & 34.9 & 18.7 & 35.6 & 91 & 0.34 & 3.2 & 2.4 & 5.5 & $0.069 \S$ \\
\hline & 2.4 & 0.6 & 0.5 & 0.8 & 0.6 & 1.3 & 5 & 0.02 & 0.1 & 0.2 & 0.3 & 0.009 \\
\hline$P$ value* & $<0.01$ & $>0.05$ & $>0.10$ & $>0.10$ & $<0.025$ & $>0.05$ & $<0.025$ & $>0.50$ & $<0.001$ & $<0.025$ & $<0.005$ & $<0.001$ \\
\hline$P$ value $\$$ & $>0.50$ & $>0.50$ & $>0.50$ & $>0.50$ & $>0.50$ & $>0.20$ & $>0.50$ & $>0.40$ & $>0.50$ & $>0.50$ & $>0.50$ & $>0.50$ \\
\hline
\end{tabular}

Values are expressed as means $\pm 1 \mathrm{SE}$.

* Calculated from paired data for the values of group 1 vs. 2.

\$ Calculated from unpaired data for the values of group 2 vs. 3 .

$\S$ Denotes means $\pm 1 \mathrm{SE}$ of the minimum $K_{\mathrm{f}}$ value determined in each rat.

as measured in groups 1-3. As with whole kidney GFR, values for SNGFR were some 35\% lower, on average, in group 1 than in group 2 . The mean value for $Q_{A}$ was $25 \%$ lower in group 1 than in group 2 . SNFF in group 1 was therefore nearly the same as in group 2. Values for $\overline{\mathrm{P}}_{\mathrm{GC}}$ did not differ significantly between groups 1 and 2 . Likewise, hydraulic pressures in proximal tubules, $\mathrm{P}_{\mathrm{T}}$, were essentially the same in groups 1 and 2 , so that mean values for $\overline{\Delta P}$ were also essentially the same in these groups. As shown in Table II, values for $\Pi_{A}$ and $\Pi_{E}$ were slightly lower in group 1 than in group 2 . Thus, whereas the mean value for $\Pi_{E}$ essentially equalled $\overline{\Delta \mathrm{P}}$ in group $2, \Pi_{\mathrm{E}}$ was uniformly lower in group 1 rats, denoting filtration pressure disequilibrium in group 1 but not in group 2 rats. Unique values for $K_{f}$ could therefore be calculated only in group 1 . The mean of the unique values for $\mathrm{K}_{\mathrm{f}}$ obtained in group 1 averaged $0.034 \pm 0.003 \mathrm{nl} /(\mathrm{s} \cdot \mathrm{mm} \mathrm{Hg})$, a value nearly $50 \%$ lower than the mean minimum $K_{f}$ value calculated in group $2(0.065 \pm 0.006)$. In group 1 animals, $R_{A}, R_{E}$, and $R_{T A}$ averaged $4.3 \pm 0.3 \times 10^{10} \mathrm{dyn} \cdot \mathrm{s} \cdot \mathrm{cm}^{-5}$, $3.4 \pm 0.2$, and $7.7 \pm 0.5$, respectively. These values are $20-35 \%$ higher than the corresponding values in group 2 animals.

As shown in Table II, average values for SNGFR and its determinants were essentially identical in group 2 and 3 animals. As in group 2, filtration pressure equilibrium was achieved in group 3 animals. Minimum $\mathrm{K}_{\mathrm{f}}$ values calculated in group 3 averaged $0.069 \pm 0.009$ $\mathrm{nl} /(\mathrm{s} \cdot \mathrm{mm} \mathrm{Hg})$, essentially identical to that in group 2. Measurements of plasma volume and erythrocyte volume. Table III summarizes average values for plasma and erythrocyte volumes measured in five pairs of animals from groups 1 and 2 . When corrected for body weight, average values for circulating erythrocyte volume (RCV), plasma volume (PV), and whole blood volume (BV) were numerically similar in groups 1 and 2 . The values for RCV and PV measured in groups 1 and 2 are slightly higher than those previously measured in identical species of rats fed regular rat chow (4). Most likely, these differences reflect the loss of peripheral fat stores in groups 1 and 2 rats maintained on calorierestricted diets. As shown in Table III, the ratio of RCV:BV essentially equaled Hct values in groups 1 and 2. It is unlikely, therefore, that the slightly higher average PV value in group 1 animals was caused by a change in vascular permeability to tracer albumin (16).

\section{Morphological studies}

Glomerular cross-sectional area. Fig. 1 depicts the influence of dietary protein content on glomerular cross sectional area. In 14 matched pairs fed low or

TABLE III

Erythrocyte and Plasma Volumes in Groups 1 and 2

\begin{tabular}{lrlcrr}
\hline & Hct & RCV & PV & BV & RCV:BV \\
\hline & vol\% & \multicolumn{4}{c}{ mll100 g body $u t$} \\
Group 1 & 42.4 & 2.42 & 3.47 & 5.89 & 41.1 \\
$\quad(n=5$ rats $)$ & \pm 0.5 & 0.09 & 0.16 & 0.20 & 1.3 \\
Group 2 & 45.2 & 2.43 & 3.22 & 5.64 & 42.8 \\
$\quad(n=5$ rats $)$ & 0.4 & 0.10 & 0.02 & 0.10 & 0.7 \\
$\quad$ value $^{*}$ & $<0.005$ & $>0.50$ & $>0.20$ & $>0.20$ & $>0.10$
\end{tabular}

Values are expressed as means $\pm 1 \mathrm{SE}$. RCV, PV, BV, and RCV: BV denote circulating erythrocyte volume, plasma volume, blood volume $(\mathrm{RCV}+\mathrm{PV})$, and ratio of $\mathrm{RCV}: \mathrm{BV} \times 100$, respectively.

* Calculated from paired data by Student's $t$ test. 


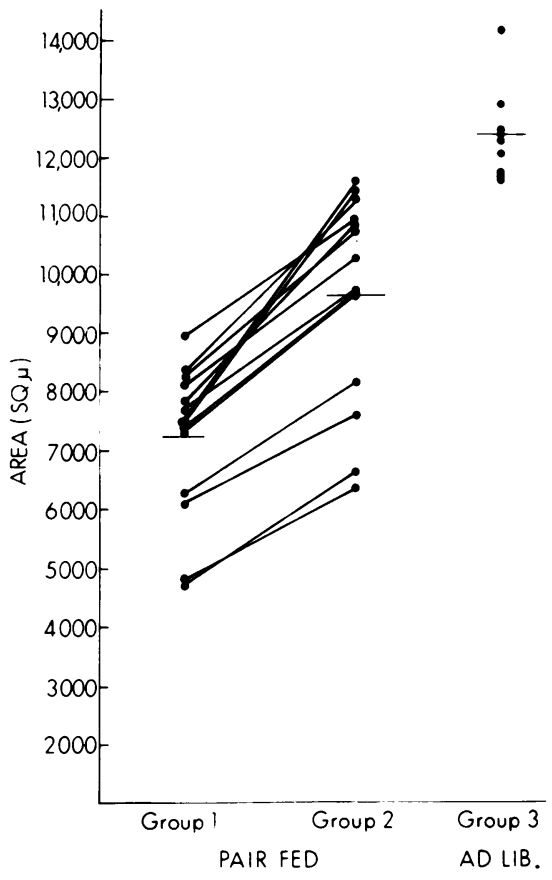

Figure 1 Glomerular cross-sectional area $\mu \mathrm{m}^{2}$ of pair-fed rats on low (group 1) and high (group 2) protein diets and of rats allowed high protein diet ad lib. (group 3). Camera lucida drawings reflect magnification $\times 417$. $P$ values were calculated from paired data for group 1 vs. group $2(P<0.001)$ and for unpaired data for group 2 vs. group $3(P<0.001)$. high protein diets, glomerular cross-sectional area averaged $7,233 \pm 344 \mu \mathrm{m}^{2}$ in group 1 rats, a value substantially lower than the average for group 2 rats $\left(9,684 \pm 476 \mu \mathrm{m}^{2}\right)$. The difference was highly significant $(P<0.001)$. In nine rats receiving the high protein diet ad lib. (group 3), the mean cross-sectional area was $12,436 \pm 279 \mu \mathrm{m}^{2}$. The difference in cross-sectional area between groups 2 and 3 was also significant $(P<0.001)$.

Light and electron microscopy. Fig. 2 presents light and transmission electron micrographs from pairfed group 1 and 2 rats allowed ad lib. intake of the high protein diet (group 3). As seen in the representative light microscopic sections, glomerular diameter appeared greatest in Fig. 2C (group 3), least in Fig. 2A (group 1) and intermediate in diameter in Fig. 2B (group 2). No other systematic differences in morphology were discovered by light microscopy. No morphological differences were noted by electron microscopy as indicated by the representative cross-sections through glomerular capillary walls from each of the three groups examined (Fig. 2D, E, and F).

\section{DISCUSSION}

A reduced GFR is one of the renal functional disturbances seen in experimental animals and human subjects with chronic protein-calorie malnutrition (1-3). Because
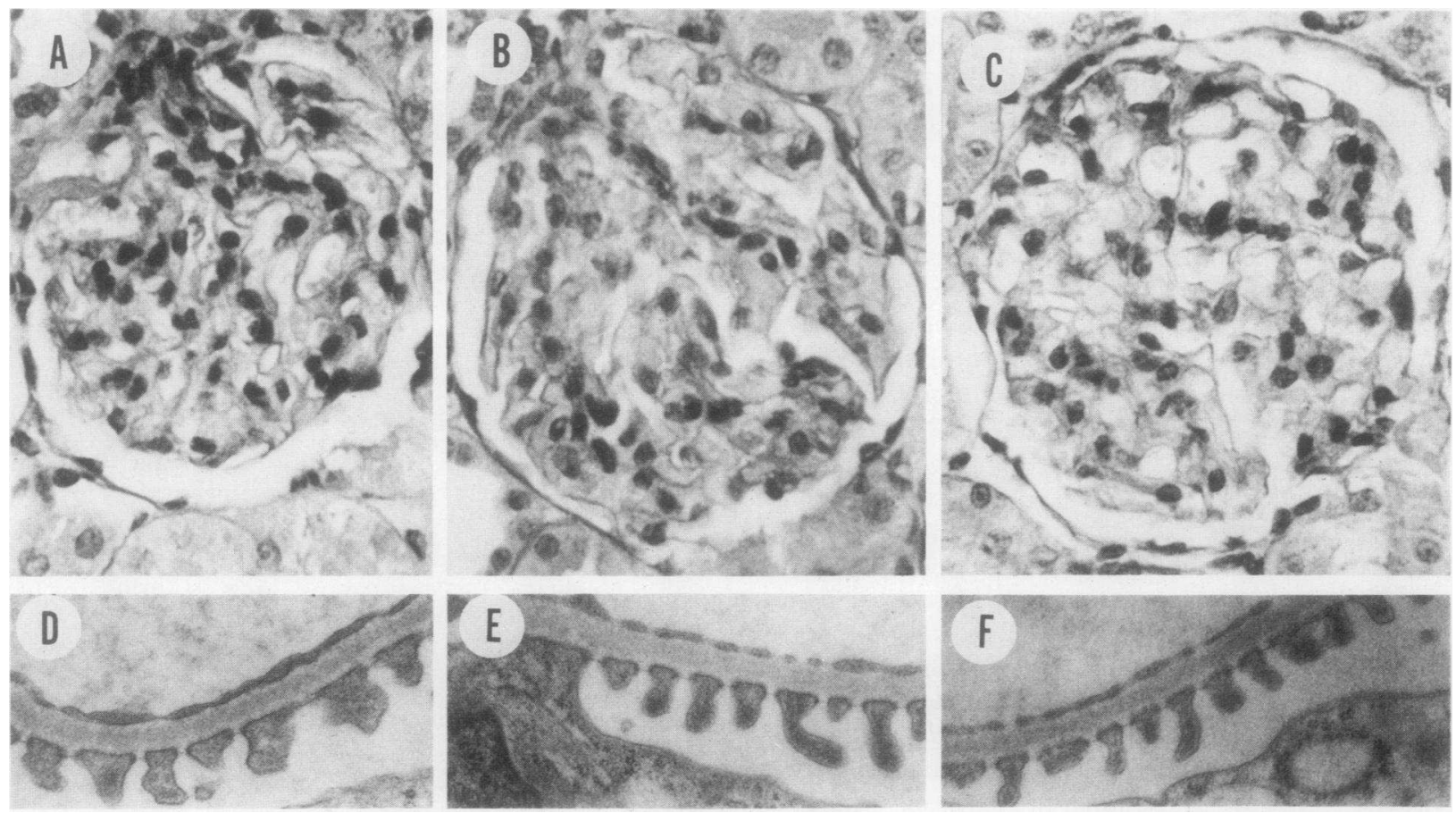

FIGURE 2 Representative light and electron photomicrographs of glomeruli and glomerular capillary walls from group $1(\mathrm{~A}, \mathrm{D})$, group $2(\mathrm{~B}, \mathrm{E})$, and group $3(\mathrm{C}, \mathrm{F}) . \mathrm{A}, \mathrm{B}$, and C: $\times 400$; $\mathrm{D}, \mathrm{E}$, and $\mathrm{F}: \times 9,050$. 
protein deficiency and total caloric deprivation frequently coexist, it is often difficult to ascertain the relative contributions of low calorie intake vs. protein deficiency in the genesis of the decreased GFR. We therefore carried out the present studies in two groups of pair-fed animals maintained on isocaloric diets of either low (group 1) or high protein content (group 2). The results obtained indicate that low protein intake per se leads to a nearly $30 \%$ average reduction in both whole kidney and SNGFR. Because the daily caloric allowance for group 2 rats was restricted so as to match the low calorie intake of the pair member on the low protein diet (group 1), total body weight gain during maturation was observed to be considerably slower in both groups than in rats which had free access to unlimited quantities of the high protein diet (group 3). Nevertheless, both whole kidney and SNGFR values were nearly identical in groups 2 and 3 when comparable body weights were achieved. Moreover, values for GFR and SNGFR in groups 2 and 3 were essentially the same as those measured previously in adult female Munich-Wistar rats fed regular rat chow ad lib. (17), indicating that calorie restriction alone, at least to the degree employed in the present study, fails to affect GFR significantly.

Of the various factors potentially responsible for the reductions in GFR and SNGFR found in rats with chronic protein malnutrition (group 1), neither $\overline{\mathrm{P}}_{\mathrm{GC}}$ nor $\mathrm{P}_{\mathrm{T}}$ was affected to a physiologically important extent. This excludes the $\overline{\Delta P}$ as an important determinant of the low filtration rates observed in group 1 animals. Inasmuch as values for $C_{A}$ (and thus $\Pi_{A}$ ) were equivalent in groups 1 and 2 , these factors can also be excluded. In contrast to this near-constancy in the values for hydraulic and oncotic pressures, we observed a significant average reduction in glomerular capillary plasma flow rate in group 1 rats, a finding in keeping with the clinical observation that, in addition to GFR, $p$-aminohippurate clearance also tends to be reduced in children and adults with severe malnutrition (1-3). Although contraction of extracellular volume has been shown to coexist in some cases of severe malnutrition (3), the near identity in average values for plasma and blood volumes in groups 1 and 2 (Table III) indicates that the malnutrition-induced reductions in renal and glomerular plasma flow rates found in group 1 rats were not simply consequences of a decreased circulating blood volume. Of course, measurements of plasma volume and total blood volume may not necessarily reflect the degree of filling of that part of the vasculature that transmits to the kidney the signals (humoral or neural) that influence the renal handling of salt and water. Nevertheless, since there is no evidence to suggest that small reductions in blood or plasma volume will reduce $Q_{A}$ or lead to filtration pressure disequilibrium (18), some other factor(s) must have been operative in determining the decline in $Q_{A}$ found in group 1 rats in the present study. Before considering these other potential factors, it is worth pointing out here that chronic protein malnutrition in the present study was also associated with a marked reduction in the glomerular $\mathrm{K}_{\mathrm{f}}$. In group 1 , because of this decline in $K_{\mathbf{f}}$ filtration pressure disequilibrium prevailed. Because the $K_{f}$ is the product of effective filtration surface area and intrinsic hydraulic permeability of the capillary wall, a decrease in either or both of these terms could account for the observed fall in $\mathrm{K}_{\mathrm{f}}$. In this regard, glomerular cross-sectional area was found to be uniformly lower in group 1 animals than in pair members fed the high protein diet (Fig. 1), suggesting that a reduction in effective filtration surface area contributed, at least in part, to the measured fall in $\mathrm{K}_{\mathrm{f}}$ in this group. When calorie intake was unrestricted in rats fed the high protein diet (group 3), glomerular cross-sectional area was even greater than in group 2 (Fig. 2). However, since group 2 animals achieved filtration pressure equilibrium, the further increment in filtration surface area seen in group 3 would not be expected to lead to further increases in GFR or SNGFR, a prediction in accord with present observations.

Although the present study does not pinpoint the specific mechanism(s) responsible for the relatively low value of $K_{f}$ in protein-malnourished rats, a number of possibilities are suggested. For example, the fall in $K_{f}$ in group 1 rats, when taken in conjunction with the measured increases in afferent, efferent, and total renal arteriolar resistances (and the consequent reduction in glomerular plasma flow rate and filtration surface areas), are reminiscent of the effects of endogenous or exogenous angiotensin II on the glomerular microcirculation. Not only has this octapeptide been shown to bind to isolated glomeruli, but it has also been demonstrated to cause mesangial cell contraction in vitro (19) and to induce changes in glomerular flows and resistances in vivo similar to those found in group 1 rats $(20,21)$. It is of interest in this respect that studies in children with severe malnutrition have demonstrated marked elevations in plasma renin activity (22). Parathyroid hormone may also play a role in the decline in $\mathrm{K}_{\mathrm{f}}$ seen in protein-malnourished rats. Although not measured in this study, parathyroid hormone levels may reasonably be expected to be higher in this group of rats than in groups 2 and 3 , because of the fixed phosphate intake and reduced GFR in group 1 rats. Yet another possible cause for the decline in $\mathrm{K}_{\mathrm{f}}$ in proteinmalnourished young rats relates to the smaller glomerular volume found in these animals, resulting in a true structural reduction in effective filtering surface area. Although a growth-dependent mechanism may be involved, this possibility seems unlikely in view of the finding that total renal weight was similar in all three groups of rats evaluated in the present study. Thus, a 
glomerulus-specific cause for reduced glomerular volume must be sought. Obviously, future studies will be required to determine whether angiotensin II, parathyroid hormone, other endogenous humoral vasoactive substances, or nutrition-related influences on glomerular structural development account for the impressive reduction in $K_{f}$ identified in protein-malnourished rats.

\section{ACKNOWLEDGMENTS}

The authors are grateful to Mrs. H. Segal for expert secretarial assistance.

These studies were supported largely by grants from the U. S. Public Health Service AM-07126, AM-09976, and A.M19467. Dr. Martinez-Maldonado is supported by a Faculty Scholar Award (1979-1980) from the Josiah Macy, Jr. Foundation and the Veterans Administration Central Office, Washington, D. C.

\section{REFERENCES}

1. Alleyne, G. A. O. 1967. The effects of severe protein caloric malnutrition on the renal function of Jamaican children. Pediatrics. 39: 400-411.

2. Klahr, S., and K. Tripathy. 1966. Evaluation of renal function in malnutrition. Arch. Intern. Med. 118: 323-325.

3. Klahr, S., and G. A. O. Alleyne. 1973. Effects of chronic protein-calorie malnutrition on the kidney. Kidney Int. 3: $129-141$.

4. Ichikawa, I., D.A. Maddox, M. G. Cogan, and B. M. Brenner. 1978. Dynamics of glomerular ultrafiltration in euvolemic Munich-Wistar rats. Renal Physiol. 1: $121-131$.

5. Vurek, G. G., and S. E. Pegram. 1966. Fluorometric method for the determination of nanogram quantities of inulin. Anal. Biochem. 16: 409-419.

6. Führ, J., J. Kaczmarczyk, and C. D. Krüttgen. 1955. Eine einfache colorimetrische methode zur inulin bestimmung für nierenclearanceuntersuchungen bei stoffwechselgesunden und diabetikern. Klin. Wochenschr. 33: 729-730.

7. Brenner, B. M., K. H. Falchuk, R. I. Keimowitz, and R. W. Berliner. 1969. Relationship between peritubular capillary protein concentration and fluid reabsorption by the renal proximal tubule.J. Clin. Invest. 48: 1519-1531.

8. Viets, J. W., W. M. Deen, J. L. Troy, and B. M. Brenner. 1978. Determination of serum protein concentration in nanoliter blood samples using fluorescamine or o-phthalaldehyde. Anal. Biochem. 88: 513-521.

9. Deen, W. M., J. L. Troy, C. R. Robertson, and B. M. Brenner. 1973. Dynamics of glomerular ultrafiltration in the rat. IV. Determination of the ultrafiltration coefficient. J. Clin. Invest. 52: 1500-1508.

10. Deen, W. M., R. Robertson, and B. M. Brenner. 1972. A model of glomerular ultrafiltration in the rat. Am. J. Physiol. 223: 1178-1183.

11. Brenner, B. M., J. L. Troy, and T. M. Daugharty. 1971. The dynamics of glomerular ultrafiltration in the rat. J. Clin. Invest. 50: 1776-1780.

12. Sterling, K., and S. J. Gray. 1950. Determination of the circulating red cell volume in man by radioactive chromium. J. Clin. Invest. 29: 1614-1619.

13. Maddox, D. A., D. C. Price, and F. C. Rector, Jr. 1977. Effects of surgery on plasma volume and salt and water excretion in rats. Am. J. Physiol. 233: F60)-F606.

14. Crispell, K. R., B. Porter, and R. T. Nieset. 1950. Studies of plasma volume using human serum albumin tagged with radioactive iodine ${ }^{131}$. J. Clin. Invest. 29: $513-516$

15. Cowan, W. M., and D. F. Wann. 1973. A computer system for the measurement of cell and nuclear sizes. J. Microsc. (Oxf.). 99: 331-348.

16. Jaenike, J. R., B. F. Schreiner, and C. Waterhouse. 1957. The relative volumes of distribution of $I^{131}$-tagged albumin and high molecular weight dextran in normal subjects and patients with heart disease. J. Lab. Clin. Med. 49: $172-181$.

17. Ichikawa, I., and B. M. Brenner. 1979. Local intrarenal vasoconstrictor-vasodilator interactions in mild partial ureteral obstruction. Am. J. Physiol. 236: F1.31-F140.

18. Schor, N., I. Ichikawa, and B. .I. Brenner. 1980. Gomerular adaptations to chronic dietary salt restriction or excess. Am. J. Physiol. In press.

19. Sraer, J. D., J. Sraer, R. Adraillou, and O. Mimoune. 1974. Evidence for renal glomerular receptors for angiotensin II. Kidney Int. 6: 241-246.

20. Blantz, R. C., K. S., Konnen, and B. J. Tucker. 1976. Angiotensin II effects upon the glomerular microcirculation and ultralfiltration coefficient of the rat. J. Clin. Invest. 57: 419-434.

21. Hall, J. E., A. C. Guyton, T. E. Jackson, T. G. Coleman, T. E. Lohmeier, and N. C. Trippodo. 1977. Control of glomerular filtration rate by renin angiotensin system. Am. J. Physiol. 233: F366-F372.

22. Kritzinger, E. E., E. Kanengoni, and J. J. Jones. 1972. Effective renin activity in plasma of children with Kwashiorkor. Lancet. I: 412-413. 